\title{
Overview about the use of Fourier Transform Infrared spectroscopy to study cementitious materials
}

\author{
M. Horgnies, J. J. Chen \& C. Bouillon \\ Lafarge Centre de Recherche, St Quentin-Fallavier, France
}

\begin{abstract}
Fourier-Transform Infrared (FT-IR) spectroscopy shows several advantages that make it interesting to investigate cementitious materials: from clinker or hydrated phases to the bulk or the surface of hardened concrete. The FT-IR analyses in Transmission mode need only a few milligrams of material to provide its composition while other techniques (such as thermo-gravimetric analysis, X-ray diffraction, X-ray fluorescence) need a few grams. Moreover, FT-IR analyses are rapid and give results after a few minutes while other methods need at least a few hours to study one sample. The analyses done in Attenuated Total Reflection mode allow studying the surface of materials without any specific sampling methods (such as cleaning with solvent or storage under vacuum), which can alter the final composition. Clinker and anhydrous cement phases were already studied in 70 s to establish the specific peaks of alite, belite and calcium aluminate. The study of major hydrates has been largely performed for the last two decades. FT-IR spectroscopy highlights easily the presence of portlandite $\left(\mathrm{Ca}(\mathrm{OH})_{2}\right)$, which is detected by a thin unique peak. Moreover, the shift of the peaks assigned to Calcium Silicate Hydrate (C-S-H) can be detected using transmission mode, in order to study the polymerization of the silicates according to the conditions of cure and ageing. AFt and AFm phases (such as ettringite, sulfoaluminate or hemicarbonate) can also be studied using FT-IR spectroscopy. Finally, this method is also able to detect organic demolding agents or $\mathrm{CaCO}_{3}$ efflorescences at the surface of hardened concrete and can be used to study the interface between the hydrated paste and the polymers or coatings.

Keywords: FT-IR, clinker phases, hydrates, C-S-H, afwillite, cement paste, concrete.
\end{abstract}




\section{Introduction}

This work deals with the description of the advantages and limits of the FT-IR spectroscopy to analyze the cementitious materials. Contrary to organic solutions, polymers and coating, the Fourier-Transform Infrared (FT-IR) spectroscopy is not usually used to study cementitious materials. Indeed, researchers prefer to characterize these materials using other methods such as thermo-gravimetric analysis (TGA), X-ray diffraction (XRD), X-ray fluorescence $(\mathrm{XRF})$...etc [1]. However, FT-IR spectroscopy was already used in 70 ' to characterize the clinker phases and shows several advantages that make it useful to study a large range of cementitious materials.

In this paper, several applied results are described in parallel of a short bibliographic review. First, the main analytical modes available on a FT-IR spectrometer are rapidly described: (i) transmission mode (Tr); (ii) Attenuated Total Reflection mode (ATR); and (iii) diffuse reflectance spectroscopy (DRIFTS). The advantages and limits of FT-IR spectroscopy to study the cementitious materials are then specified. In a second part, a brief overview of the scientific literature is presented in parallel of selected FT-IR results for each topic (clinker phases, anhydrous cement, synthetic hydrates, hydrated cement paste, bulk of mortar and concrete surface).

\section{Presentation of the FT-IR spectroscopy}

\subsection{Main modes of analyses}

The FT-IR results shown in this work were obtained using a Nicolet iS10 spectrometer (Thermo Fisher Scientific Inc.). It was equipped with a deuterated triglycine sulfate (DTGS) detector and controlled by OMNIC software.

In Transmission mode (Tr), our sampled pellets were manufactured by mixing $250 \mathrm{mg}$ of potassium bromide (KBr) with $3 \mathrm{mg}$ of material (clinker or cement powder, or powder directly sampled into the bulk of hardened samples). 16 scans were recorded over the range $4,000-400 \mathrm{~cm}^{-1}$ with a spectral resolution of $4 \mathrm{~cm}^{-1}$. The background spectrum was collected using a pure $\mathrm{KBr}$ pellet and the spectra of samples were corrected with a linear baseline.

In Attenuated Total Reflexion (ATR) mode, our hardened samples were directly analyzed over a thickness of a few $\mu \mathrm{m}$ and a sampling area of about $1 \mathrm{~mm}^{2}$. The crystal used was made of diamond. 16 scans were routinely recorded over the range 4000-650 $\mathrm{cm}^{-1}$ with a spectral resolution of $4 \mathrm{~cm}^{-1}$. The background spectrum was collected at ambient atmosphere before analyzing each sample. The spectra of hardened samples were corrected with a linear baseline.

The diffuse reflectance infrared Fourier transform spectroscopy (DRIFTS) allowed measuring a range between 400 and $4000 \mathrm{~cm}^{-1}$. The incident beam was reflected off the ground sample towards an overhead mirror upon which the diffusely scattered rays were collected and measured in the detector. 


\subsection{Advantages and limits compared to other methods}

\subsubsection{Main advantages}

First, the analyses in Transmission mode need only a few milligrams of material to provide its composition while other techniques need a few grams. This specific light sampling is particularly relevant when only a small mass of hydrates can be synthesized. It is also easy to sample the cement paste into the bulk of mortar/concrete without any contamination from sand or aggregates.

Second, FT-IR results are directly obtained a few minutes after analyses without any complex treatment while other methods (TGA, XRD, XRF...etc) need at least a few hours to study one sample.

Third, the analyses in Attenuated Total Reflection (ATR) mode allow studying the surface of the cementitious materials without any specific sampling methods (such as cleaning with solvent or storage under vacuum, which can modify the composition of the material).

\subsubsection{Main limits}

FT-IR spectroscopy cannot be considered such as a quantifying method. Even if the intensity of certain specific IR bands, such as the one of portlandite, can vary as a function of their content in the sample (semi-quantification), it is not possible to make the relation between the intensity or the area of an IR band and a specific ratio.

Moreover, traces of chemical compounds can be under-estimated or erased due to the high intensity of certain IR bands, such as those of silica or calcium carbonate.

Finally, the presence of a large amount of capillary water into the hydrated sample can mask certain chemical compounds and disturb the interpretation of the spectra.

\section{Selection of results obtained on cementitious materials}

\subsection{Analyses of anhydrous clinker phases}

Clinker and anhydrous cement phases were already studied in the 70s in order to characterize the IR bands of alite, belite and calcium aluminate. Bensted and Varma [2], and Ghosh and Chatterjee [3, 4] published in 1974 certain of the first main papers about the FT-IR analyses applied in the cement industry. Ghosh and Handoo [5] wrote one of the first review papers in 1980. These first papers were mainly devoted to the analyses using transmission mode (only [4] used ATR mode).

Table 1 and Figure 1 show our own analyses done in Transmission mode concerning the specific peaks of synthetic clinker phases. Indeed, pure $\mathrm{Ca}_{3} \mathrm{SiO}_{5}$ and $\mathrm{Ca}_{2} \mathrm{SiO}_{4}$ phases were prepared by successive heating (at $1600^{\circ} \mathrm{C}$ ) of a mixture of finely divided calcium carbonate (from Sigma-Aldrich, Germany) and silica (Aerosil 200 from Degussa, France) with appropriate stoichiometric proportions. All the spectra are conformed to those found in literature [2-5]. 
A double peak at $995-900$ and $938-883 \mathrm{~cm}^{-1}$, assigned to $\mathrm{Si}-\mathrm{O}$ asymmetric stretching vibrations, characterizes mainly $\mathrm{C} 2 \mathrm{~S}$ and $\mathrm{C} 3 \mathrm{~S}$ phases, respectively. The detection of ferrite phase is difficult due to the absence of resolved and fixed peaks but aluminates phase $(\mathrm{C} 3 \mathrm{~A})$ is easier to detect due to a large set of thin peaks assigned to Al-O bond.

Table 1: $\quad$ FT-IR bands of the synthetic clinker phases.

\begin{tabular}{|c|c|c|c|c|c|c|c|}
\hline \multirow{3}{*}{$\begin{array}{c}\begin{array}{c}\text { Clinker } \\
\text { phases }\end{array} \\
\begin{array}{c}\mathrm{C} 3 \mathrm{~S}- \\
\mathrm{Ca}_{3} \mathrm{SiO}_{5}\end{array}\end{array}$} & \multicolumn{7}{|c|}{$\begin{array}{l}\text { Wave-number }\left(\mathrm{cm}^{-1}\right) \text { with intensity of the band } \\
\text { (s: strong; m: medium; } 1 \text { : low) }\end{array}$} \\
\hline & \multirow{2}{*}{$\begin{array}{c}\text { Si-O } \\
938 \mathrm{~s} \\
883 \mathrm{~s}\end{array}$} & \multirow[t]{2}{*}{ Al-O } & \multirow{2}{*}{$\frac{\mathrm{Si}-\mathrm{O}}{8121}$} & \multirow[t]{2}{*}{$\mathrm{Al}-\mathrm{O}$} & \multicolumn{3}{|c|}{ Si-O } \\
\hline & & & & & $\begin{array}{c}522 \\
\mathrm{~s}\end{array}$ & & $430 \mathrm{~s}$ \\
\hline $\begin{array}{l}\mathrm{B}-\mathrm{C} 2 \mathrm{~S}- \\
\mathrm{Ca}_{2} \mathrm{SiO}_{4}\end{array}$ & $\begin{array}{l}995 \mathrm{~s}, \\
900 \mathrm{~s}\end{array}$ & & $\begin{array}{r}844 \mathrm{~s}, \\
8101\end{array}$ & & $\begin{array}{c}518 \\
\mathrm{~s}\end{array}$ & & \\
\hline $\begin{array}{c}\mathrm{C} 3 \mathrm{~A}- \\
\mathrm{Ca}_{3} \mathrm{Al}_{2} \mathrm{O}_{6}\end{array}$ & & $898 \mathrm{~s}$ & $817 \mathrm{~s}$ & $\begin{array}{c}7861,739 \mathrm{~s}, 704 \mathrm{~s}, 5881, \\
521 \mathrm{~s}\end{array}$ & & $456 \mathrm{~s}$ & \\
\hline $\begin{array}{c}\mathrm{C} 4 \mathrm{AF}- \\
\mathrm{Ca}_{4} \mathrm{Al}_{2} \mathrm{Fe}_{2} \mathrm{O}_{10}\end{array}$ & & & & orly resolved bands & & & \\
\hline
\end{tabular}

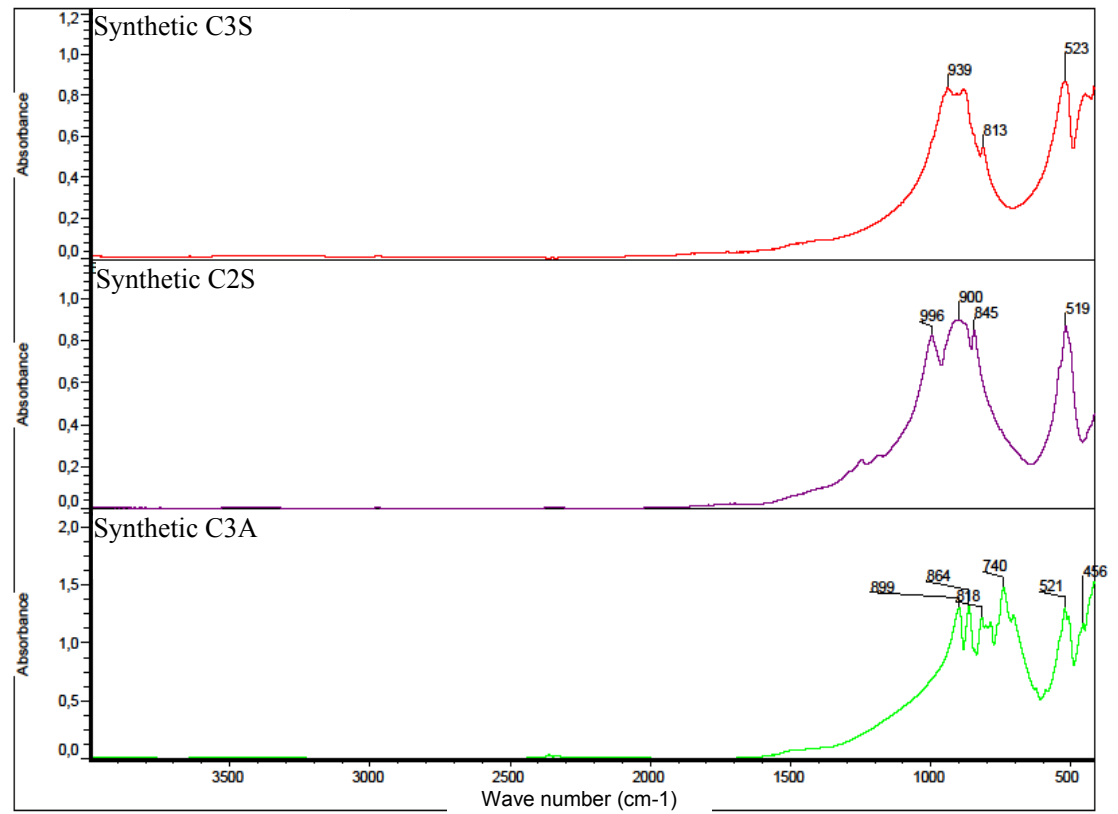

Figure 1: $\quad$ IR spectra of synthetic C3S, C2S and C3A. 


\subsection{Analyses of hydrated cement phases}

\subsubsection{Detection of the main hydrated phases}

FT-IR spectroscopy highlights easily the presence of portlandite $\left(\mathrm{Ca}(\mathrm{OH})_{2}\right)$, which is well detected by a resolute unique peak at $3640 \mathrm{~cm}^{-1}$. This method is also used to study the shift of the bands assigned to Calcium Silicate Hydrate (C$\mathrm{S}-\mathrm{H})$ according to the conditions of cure and ageing.

Table 2: $\quad$ FT-IR bands of the main hydrated phases.

\begin{tabular}{|c|c|c|c|c|c|c|c|}
\hline \multirow{2}{*}{$\begin{array}{c}\text { Main } \\
\text { hydrated } \\
\text { phases }\end{array}$} & \multicolumn{7}{|c|}{$\begin{array}{l}\text { Wave-number }\left(\mathrm{cm}^{-1}\right) \text { with intensity of the band } \\
\qquad(\mathrm{s}=\text { strong; } \mathrm{m}=\text { medium; } \mathrm{l}=\text { low })\end{array}$} \\
\hline & $\mathrm{O}-\mathrm{H}$ & $\begin{array}{c}\mathrm{O}-\mathrm{H} \\
\mathrm{H}_{2} \mathrm{O} \text { capil. }\end{array}$ & $\begin{array}{r}\mathrm{Si}-\mathrm{C} \\
\text { (asym. str } \\
\text { vib. }\end{array}$ & hing & Si-O & $\begin{array}{c}\text { Si-O } \\
\text { (out-of plane } \\
\text { vib.) }\end{array}$ & $\begin{array}{l}\text { Si-O } \\
\text { (in- } \\
\text { plane } \\
\text { vib.) }\end{array}$ \\
\hline $\begin{array}{l}\text { Afwillite (crystalline micro- } \\
\text { structure; } \mathrm{Ca} / \mathrm{Si} \text { ratio=1.5) }\end{array}$ & & $\begin{array}{l}33521 \\
16601\end{array}$ & $\begin{array}{l}985 \mathrm{~m} \\
963 \mathrm{~s}\end{array}$ & $\begin{array}{c}911 \\
\mathrm{~S}\end{array}$ & $\begin{array}{l}860 \mathrm{~m}, \\
781 \mathrm{~m}\end{array}$ & $\begin{array}{c}617 \mathrm{~m}, \\
520 \mathrm{~s} \\
490 \mathrm{~s}\end{array}$ & $450 \mathrm{~s}$ \\
\hline $\begin{array}{l}\mathrm{C}-\mathrm{S}-\mathrm{H} \text { (colloidal gel like } \\
\text { structure; } \mathrm{Ca} / \mathrm{Si} \text { ratio=1.5) }\end{array}$ & & $\begin{array}{l}33561 \\
16401\end{array}$ & $\begin{array}{c}1000 \mathrm{~s} \\
950 \mathrm{~s}\end{array}$ & $\begin{array}{c}950 \\
\mathrm{~s}\end{array}$ & $\begin{array}{c}814 \\
\mathrm{~m}\end{array}$ & $\begin{array}{l}6671 \\
496 \mathrm{~s}\end{array}$ & $456 \mathrm{~s}$ \\
\hline $\begin{array}{c}\text { Portlandite - } \\
\mathrm{Ca}(\mathrm{OH})_{2}\end{array}$ & $\begin{array}{c}3642 \\
\mathrm{~s}\end{array}$ & & & & & & \\
\hline
\end{tabular}

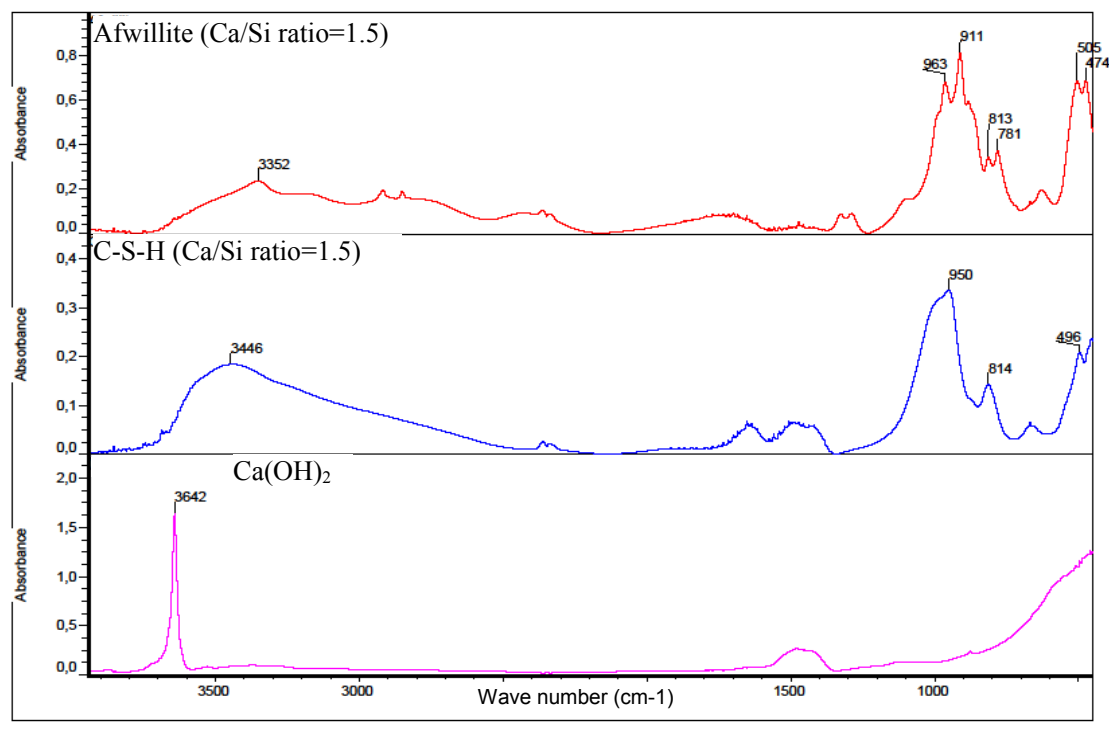

Figure 2: IR spectra of synthetic $\mathrm{Ca}(\mathrm{OH})_{2}, \mathrm{C}-\mathrm{S}-\mathrm{H}(\mathrm{Ca} / \mathrm{Si}=1.5)$ and afwillite.

Table 2 and Figure 2 provide our own analyses done in Transmission mode on synthetic hydrated phases. The $\mathrm{Ca}(\mathrm{OH})_{2}$ (portlandite) was provided directly 
by a supplier (Sigma-Aldrich) while the calcium silicate hydrates (C-S-H, a colloidal gel like structure [6]) were prepared by mixing $\mathrm{CaO}$ (Sigma-Aldrich) and pure silica (Aerosil 200 from Degussa) with a calcium/silicon ratio of 1.5 and 0.9. A crystalline calcium silicate hydrate (afwillite) was also manufactured using a grinding process with ball milling and a calcium/silicon ratio of 1.5 [7]. The main IR bands of our powder samples made of C-S-H or afwillite are conformed to those detected in literature [8].

\subsubsection{Shift due to the silica polymerization of C-S-H}

The main characteristic peaks of C-S-H are located in the range between 1100 and $900 \mathrm{~cm}^{-1}$. During ageing and de-calcification process, these IR bands shift according to the process of polymerization of the silica [9].

García-Lodeiro et al. [10,11] and Bhat and Debnath [12] studied the hydration of C-S-H gel by FT-IR (in transmission mode). An interesting deconvolution of Si-O asymmetric stretching bands has been done [11].

Moreover, Ylmén et al. [13, 14] performed FT-IR analyses by DRIFTS to study different types of C-S-H according to the hydration time.

Hughes et al. [15] summarized the different assignment of IR bands (detected by DRIFTS) concerning the cement before and after hydration (clinker phases, sulfate-based and hydrated/carbonated products). The authors highlighted that the peak area of $\mathrm{O}-\mathrm{H}$ of $\mathrm{Ca}(\mathrm{OH})_{2}$ was proportional to the peak area of $\mathrm{Ca}(\mathrm{OH})_{2}$ measured by TGA.

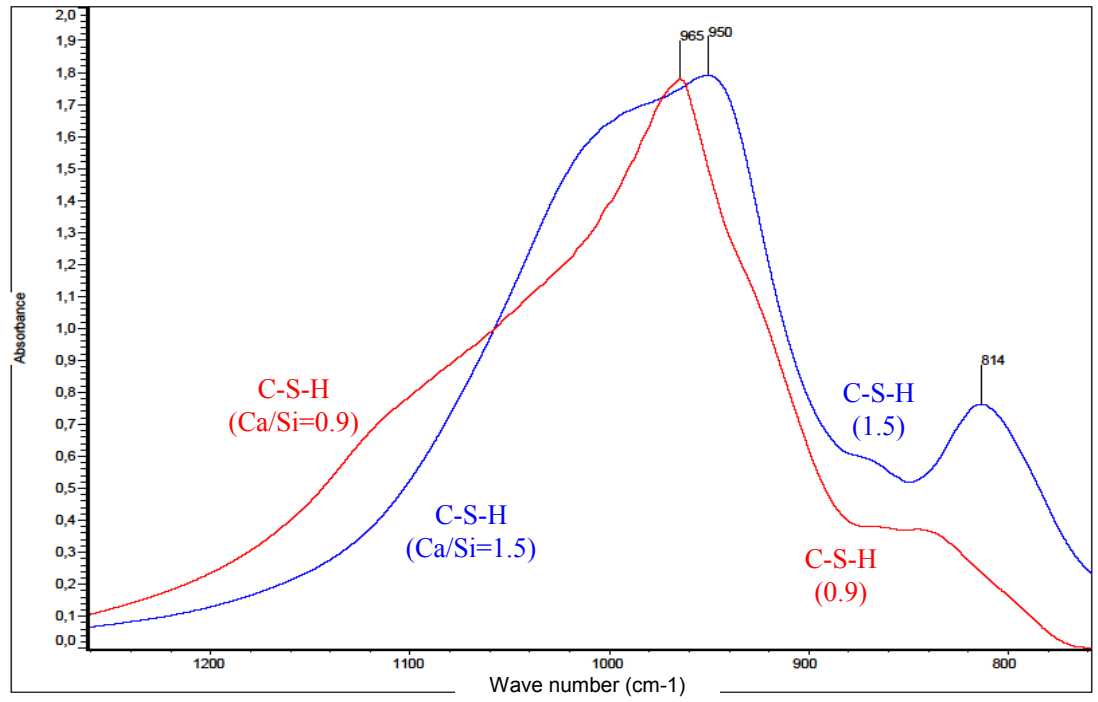

Figure 3: $\quad$ Main IR bands of C-S-H (1.5) and C-S-H (0.9). 
Yu et al. [16] investigated the structure of different synthetic C-S-H. The FTIR spectra of their C-S-H were compared to those of tobermorite in order to establish that the IR bands of C-S-H (between 980 and $1080 \mathrm{~cm}^{-1}$ ) varied according to the calcium/silicon ratio. Indeed, the $1100-950 \mathrm{~cm}^{-1}$ region (assigned to $\mathrm{Si}-\mathrm{O}$ stretching) shifted to lower wave-numbers due to the decreasing polymerization.

Figure 3 shows the IR bands of our synthetic C-S-H samples in the 1300 $700 \mathrm{~cm}^{-1}$ range. The spectrum of C-S-H 1.5 (calcium/silicon ratio of 1.5), which is usually found in young hardened cement paste, is then compared to the one of aged C-S-H (calcium/silicon ratio of 0.9). A shift of the bands to higher wave numbers is then highlighted after ageing, due to the polymerization of silica during the de-calcification process.

\subsubsection{Detection of the Aft/AFm phases}

A part of the actual studies done using FT-IR spectroscopy is devoted to the investigation of $\mathrm{Aft}$ and $\mathrm{AFm}$ phases (such as ettringite, sulfoaluminate, hemicarbonate, monosulfoaluminate, $\mathrm{C} 4 \mathrm{AH} 13 \ldots$...tc), which can be responsible for an anticipated ageing of the hydrated cement paste. For example, precipitation of secondary ettringite can be responsible for the swelling, the fissuring and the decreasing of the mechanical resistance of concrete [17].

Certain works are focused on the evolution of the hydration when silica fumes and fly ash are added into the cement paste. Hidalgo Lopez et al. [18] showed by FT-IR in transmission mode certain phases formed in the hydrated pastes, such as Stratlingite (C2ASH8), hydrogarnet (C3AH6), gibbsite $\left(\mathrm{Al}(\mathrm{OH})_{3}\right)$ and hydrated tetracalcium aluminate $(\mathrm{C} 4 \mathrm{AcH} 11)$.

We performed FT-IR analyses in transmission mode on different synthetic $\mathrm{Aft} / \mathrm{AFm}$ phases (created using specific mixes made of pure $\mathrm{AlSO}_{4}, \mathrm{CaO}$, $\mathrm{Ca}(\mathrm{OH})_{2}, \mathrm{CaCO}_{3}, \mathrm{C} 3 \mathrm{~A}$ and/or gypsum and processed at distinct temperatures). Table 3 provides the assignment of IR bands of the spectra of ettringite, monocarbo-aluminate, hemi-carbo-aluminate, mono-sulfo-aluminate, C4AH13, C3AH6 (hydrogarnet) and C2ASH8 (stratlingite). The contaminations due to the process of synthesis were deduced by using XRD analyses and were removed (e.g. ettringite in sulfo-aluminate or portlandite in hemi-carbo-aluminate). All these phases show complex spectra (as shown in Figure 4) due to the presence of aluminate, sulfate and carbonate units. We notice that both the IR spectra of hemi- and mono-carbo-aluminates are equivalent.

\subsection{Analyses of the bulk and surface of hardened pastes}

FT-IR spectroscopy is mainly known for its efficiency to characterize polymer or organic compounds [19]. This specific ability can be useful to: (i) investigate the bulk of lightweight mortar containing aggregates made of polymer waste; (ii) detect residues of demolding agents (e.g. based on vegetable base oil) [20]; (iii) highlight the presence of $\mathrm{CaCO}_{3}$ efflorescences [21]; (iv) study the interface between concrete and protective coating [21]. 
Table 3: FT-IR bands of Aft/AFm phases (contamination due to the creation process deduced).

\begin{tabular}{|c|c|c|c|c|c|c|c|c|c|c|}
\hline \multirow{2}{*}{$\begin{array}{l}\mathrm{AFt} / \mathrm{AFm} \\
\text { phases }\end{array}$} & \multicolumn{10}{|c|}{$\begin{array}{l}\text { Wave-number }\left(\mathrm{cm}^{-1}\right) \text { with intensity of the band } \\
(\mathrm{s}=\text { strong; } \mathrm{m}=\text { medium; l=low) }\end{array}$} \\
\hline & \multicolumn{3}{|c|}{$\mathrm{O}-\mathrm{H}$} & \multirow{2}{*}{ 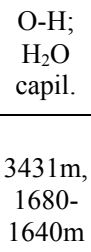 } & \multirow{2}{*}{\begin{tabular}{|c|}
$\mathrm{C}-\mathrm{O} ;$ \\
{$\left[\mathrm{CO}_{3}\right]^{2}$}
\end{tabular}} & \multirow{2}{*}{$\begin{array}{c}\mathrm{S}-\mathrm{O} ; \\
{\left[\mathrm{SO}_{4}\right]^{2-}}\end{array}$} & \multirow[t]{2}{*}{ Si-O } & \multicolumn{3}{|c|}{$\mathrm{Al}-\mathrm{O}$} \\
\hline $\begin{array}{c}\text { Ettringite } \\
\mathrm{Ca}_{6} \mathrm{Al}_{2}\left(\mathrm{SO}_{4}\right)_{3}(\mathrm{OH})_{12} / \\
26 \mathrm{H}_{2} \mathrm{O}\end{array}$ & & $3637 \mathrm{~s}$ & & & & & & 8571 & & $537 \mathrm{~m}$ \\
\hline $\begin{array}{c}\text { Mono-Carbo- } \\
\text { aluminate } \\
\mathrm{Ca}_{4} \mathrm{Al}_{2}\left(\mathrm{CO}_{3}\right)(\mathrm{OH})_{12} / \\
5 \mathrm{H}_{2} \mathrm{O}\end{array}$ & $3676 \mathrm{~m}$ & $3624 \mathrm{~m}$ & $3543 \mathrm{~m}$ & $\begin{array}{c}3363 \mathrm{~m}, \\
3005 \mathrm{~m}, \\
16501\end{array}$ & $1363 \mathrm{~s}$ & & & $953 \mathrm{~m}$ & 6691 & $535 \mathrm{~s}$ \\
\hline $\begin{array}{c}\text { Hemi-Carbo- } \\
\text { aluminate } \\
\mathrm{Ca}_{4} \mathrm{Al}_{2}\left(\mathrm{CO}_{3}\right)_{0.5}(\mathrm{OH})_{13} \\
/ 5.5 \mathrm{H}_{2} \mathrm{O}\end{array}$ & $3676 \mathrm{~m}$ & $3642 \mathrm{~m}$ & $3544 \mathrm{~m}$ & $\begin{array}{c}3367- \\
3007 \mathrm{~m}, \\
16451\end{array}$ & $1364 \mathrm{~s}$ & & & $954 \mathrm{~m}$ & 6711 & $537 \mathrm{~s}$ \\
\hline $\begin{array}{c}\text { Mono-sulfo- } \\
\text { aluminate } \\
\mathrm{Ca}_{4} \mathrm{Al}_{2}\left(\mathrm{SO}_{4}\right)(\mathrm{OH})_{12} / \\
6 \mathrm{H}_{2} \mathrm{O} \\
\end{array}$ & $3672 \mathrm{~m}$ & & $3549 \mathrm{~m}$ & $\begin{array}{l}3423 \mathrm{~s}, \\
1650 \mathrm{~m}\end{array}$ & 13801 & $1150 \mathrm{~m}$ & & & $579 \mathrm{~m}$ & $525 \mathrm{~s}$ \\
\hline $\begin{array}{c}\mathrm{C} 4 \mathrm{AH} 13 ; \\
\mathrm{Ca}_{4} \mathrm{Al}_{2}(\mathrm{OH})_{14} / 6 \mathrm{H}_{2} \mathrm{O}\end{array}$ & $3673 \mathrm{~m}$ & & $3541 \mathrm{~m}$ & $\begin{array}{r}3400 \mathrm{~m}, \\
16411\end{array}$ & 13831 & & & & 6671 & $522 \mathrm{~s}$ \\
\hline $\begin{array}{c}\text { C3AH6 } \\
\text { (Hydrogarnet); } \\
\mathrm{Ca}_{3} \mathrm{Al}_{2}(\mathrm{OH})_{12}\end{array}$ & $3660 \mathrm{~s}$ & & & & & & & 8101 & & $537 \mathrm{~s}$ \\
\hline $\begin{array}{c}\mathrm{C} 2 \mathrm{ASH} 8 \\
(\mathrm{Stratlingite}) ; \\
\mathrm{Ca}_{2} \mathrm{Al}_{2} \mathrm{SiO}_{2}(\mathrm{OH})_{10} / \\
2.25 \mathrm{H}_{2} \mathrm{O}\end{array}$ & 36691 & & & $\begin{array}{c}3442 \mathrm{~m}, \\
16521\end{array}$ & & & $\begin{array}{c}1050 \mathrm{~s}, \\
452 \mathrm{~s}\end{array}$ & $951 \mathrm{~s}$ & & $524 \mathrm{~s}$ \\
\hline
\end{tabular}

Indeed, FT-IR spectroscopy in transmission mode was used to study the bulk of lightweight mortar containing polyamide waste powder. The polymer waste powder was then recycled as aggregates to substitute $50 \%$ of the sand (in volume ratio) contained in the mortar. Table 4 describes the IR spectra obtained 28 days after demolding. Specific bands assigned to polyamide are perfectly detected (data in italic). Several samplings performed into the bulk show a homogeneous dispersion of the polymer powder into the mortar mix. Assignment of the other bands did not show any specific disturbance of hydration: portlandite was detected at $3640 \mathrm{~cm}^{-1}$ (O-H stretching vibration); $\mathrm{C}-\mathrm{S}-\mathrm{H}$ were characterized by the major bands at $1030-970 \mathrm{~cm}^{-1}$ (Si-O asymmetric stretching vibration); the $\mathrm{S}$ $\mathrm{O}$ stretching vibration of $\left[\mathrm{SO}_{4}\right]^{2-}$ was also detected at $1150-1100 \mathrm{~cm}^{-1}$. 


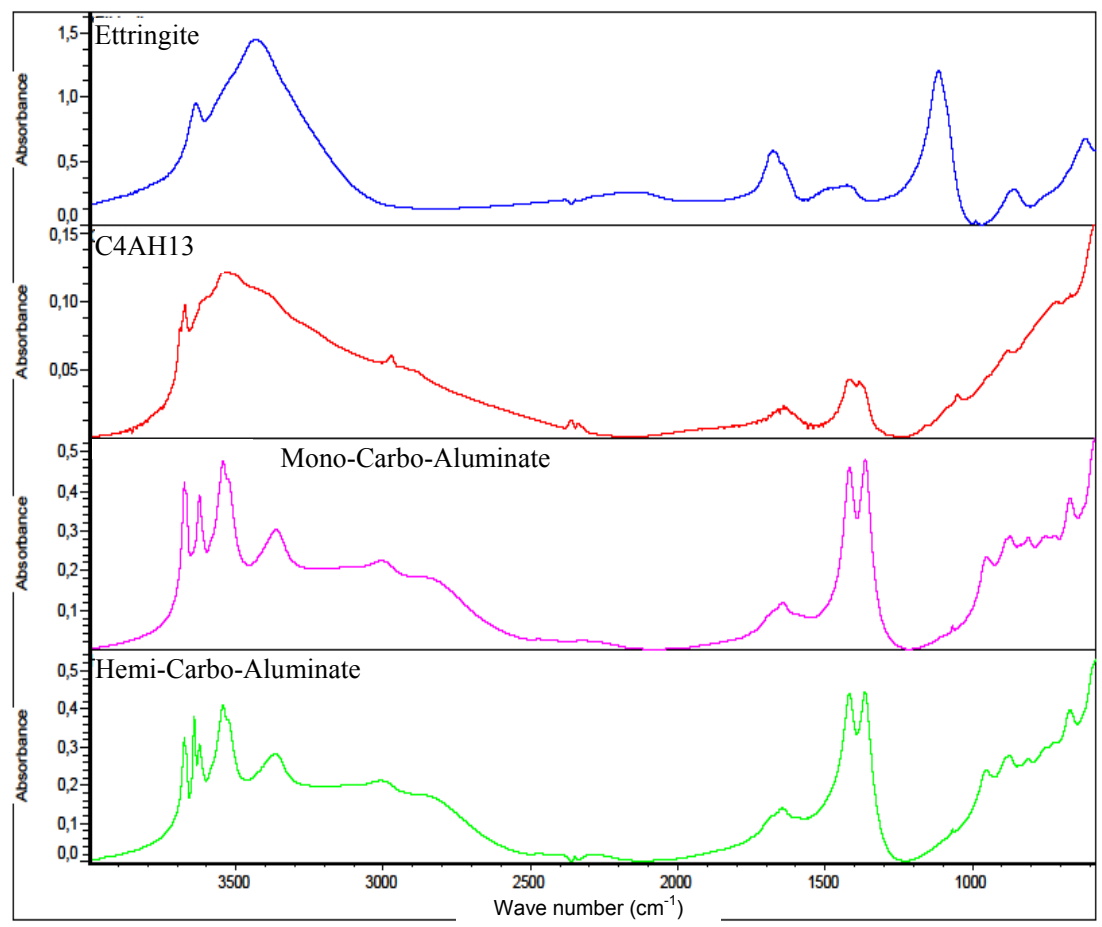

Figure 4: IR spectra of the different AFt/AFm phases studied.

Table 4: $\quad$ FT-IR bands of the bulk of mortar containing polymer recycled waste.

\begin{tabular}{|c|c|c|c|c|c|c|c|c|c|}
\hline \multirow{3}{*}{$\begin{array}{c}\text { Bulk of } \\
\text { mortar } \\
\text { containing } \\
\text { polyamide } \\
\text { waste powder }\end{array}$} & \multicolumn{9}{|c|}{$\begin{array}{l}\text { Wave-number }\left(\mathrm{cm}^{-1}\right) \text { with intensity of the band } \\
\qquad(\mathrm{s}=\text { strong; } \mathrm{m}=\text { medium; } \mathrm{l}=\mathrm{low})\end{array}$} \\
\hline & $\mathrm{O}-\mathrm{H}$ & $\begin{array}{c}\mathrm{O}-\mathrm{H} ; \mathrm{H}_{2} \mathrm{O} \\
\text { capil. }\end{array}$ & $N-H$ & $\begin{array}{l}\mathrm{CH}_{2} / \\
\mathrm{CH}_{3}\end{array}$ & $\begin{array}{c}\mathrm{C}-\mathrm{O} ; \\
{\left[\mathrm{CO}_{3}\right]^{2-}}\end{array}$ & $C=O$ & $C-N$ & $\begin{array}{c}\mathrm{S}-\mathrm{O} ; \\
{\left[\mathrm{SO}_{4}\right]^{2-}}\end{array}$ & $\begin{array}{l}\text { Si-O } \\
\text { (asym. } \\
\text { stretching } \\
\text { vib.) }\end{array}$ \\
\hline & $3640 \mathrm{~m}$ & $\begin{array}{c}3400 \mathrm{~m}, \\
16501\end{array}$ & $\begin{array}{c}3300 \mathrm{~s}, \\
3100 \mathrm{~m}, \\
1460 \mathrm{~m}\end{array}$ & $\begin{array}{l}2920 s, \\
2850 s\end{array}$ & $\begin{array}{c}25101, \\
1410 \mathrm{~s}, \\
872 \mathrm{~m}, 710 \mathrm{~s}\end{array}$ & $1640 s$ & $1560 \mathrm{~s}$ & $1100 \mathrm{~s}$ & $\begin{array}{c}1030 \mathrm{~s}- \\
970 \mathrm{~s}\end{array}$ \\
\hline
\end{tabular}

A concrete sample, protected by a polyurethane based resin, was also studied by FT-IR. The coating was sprayed on the concrete surface 28 days after demolding. The ATR mode was used to investigate the interface between concrete surface and coating. Table 5 provides the assignment of the main IR bands detected from the concrete. Portlandite (at $3640 \mathrm{~cm}^{-1}$ ) and C-S-H (1020$970 \mathrm{~cm}^{-1}$ ) were well detected. A double peak at $935-900 \mathrm{~cm}^{-1}$ was assigned to the presence of anhydrous alite. The FT-IR spectroscopy highlighted the 
presence of $\mathrm{CaCO}_{3}$ ( 3 distinct bands at 1410,870 and $\left.710 \mathrm{~cm}^{-1}\right)$. The detection of $\mathrm{CaCO}_{3}$ was assigned to the carbonation process or to the limestone filler used into the concrete mix. On the other hand, specific peaks of PU-based coating were well detected (data in italic in Table 5). No specific band attributed to the isocyanates group (at $2270 \mathrm{~cm}^{-1}$ ) was detected, confirming a complete crosslinking of the resin.

Table 5: $\quad$ FT-IR bands of the interface between concrete and PU resin.

\begin{tabular}{|c|c|c|c|c|c|c|c|c|c|c|}
\hline \multirow{3}{*}{$\begin{array}{l}\text { Interface } \\
\text { between } \\
\text { concrete } \\
\text { and a PU } \\
\text { based resin }\end{array}$} & \multicolumn{10}{|c|}{$\begin{array}{l}\text { Wave-number }\left(\mathrm{cm}^{-1}\right) \text { with intensity of the band } \\
\qquad(\mathrm{s}=\text { strong; } \mathrm{m}=\text { =medium; } 1=\text { low })\end{array}$} \\
\hline & $\mathrm{O}-\mathrm{H}$ & $\begin{array}{c}\mathrm{OH} \\
\mathrm{H}_{2} \mathrm{O} \text { capil. }\end{array}$ & $N-H$ & $\begin{array}{l}\mathrm{CH}_{2} / \\
\mathrm{CH}_{3}\end{array}$ & $\begin{array}{l}\mathrm{C}-\mathrm{O} \\
{\left[\mathrm{CO}_{3}\right]^{2-}}\end{array}$ & $C=O$ & $\begin{array}{l}\mathrm{S}-\mathrm{O} ; \\
{\left[\mathrm{SO}_{4}\right]^{2-}}\end{array}$ & \begin{tabular}{|c|}
$\begin{array}{c}\mathrm{Si}-\mathrm{O} \\
\text { (asym. } \\
\text { stretching) } \\
\text { vib. }\end{array}$ \\
\end{tabular} & Si-O & $\mathrm{Si}-\mathrm{O}$ \\
\hline & $3640 \mathrm{~m}$ & $\begin{array}{l}3400 \mathrm{~m}, \\
16501\end{array}$ & $\begin{array}{l}3335 s, \\
1450 m\end{array}$ & $\begin{array}{l}2950 s, \\
2850 s\end{array}$ & $\begin{array}{c}2510 \mathrm{l}, \\
1410 \mathrm{~s}, \\
872 \mathrm{~m}, \\
710 \mathrm{~s}\end{array}$ & $1690 \mathrm{~s}$ & $1110 \mathrm{~s}$ & $\begin{array}{c}1020 \mathrm{~s} \\
970 \mathrm{~s}\end{array}$ & $\begin{array}{l}9351, \\
9001\end{array}$ & $\begin{array}{l}797 \mathrm{~m}, \\
777 \mathrm{~m}\end{array}$ \\
\hline
\end{tabular}

\section{Conclusions}

FT-IR spectroscopy is a useful and convenient method to study the cementitious materials. This technique of characterization benefits certain advantages such as a small amount of sampling material, a short time of interpretation and a simplified sampling process compared to other usual methods of characterization. Moreover, specific modes of analysis such as ATR can directly investigate the surface of the hardened cementitious samples. However, FT-IR spectroscopy does not give any quantifying interpretation and is limited to detect the traces of certain compounds. Concerning the different applications, clinker phases and anhydrous cement can be well characterized by FT-IR in order to highlight the presence of C3S, C2S and C3A. Synthetic hydrated powders are easily investigated to detect the presence of major hydrates such as portlandite and C-S-H. The shift of the position of the major bands of C-S-H is studied to obtain specific data about the polymerization of silica and the decalcification process that occur during the ageing of the hydrated cement paste. New developments are under progress to study the presence of phases such as secondary ettringite, hemicarbonate, monosulfoaluminate, sulfoaluminate, C4AH13, etc. Finally, FT-IR spectroscopy is also interesting to characterize the mortar or concrete samples, containing or covered by polymer compounds, such as organic coatings.

\section{References}

[1] Taylor, H.F.W., Cement Chemistry, Thomas Telford Publishing, London, $2^{\text {nd }}$ Edition, 1997. 
[2] Bensted, J. and Varma, S.P., Some applications in Infrared and Raman spectral studies in cement industry (Part 2: Portland cement and its constituents). Cement Technology, pp. 378-382, July/August 1974.

[3] Ghosh, S.N. and Chatterje, A.K., Absorption and reflection infrared spectra of major cement minerals, clinker, and cements. Journal of Materials Science, 9, pp. 1577-1584, 1974.

[4] Ghosh, S.N. and Chatterje, A.K., Attenuated total reflectance spectra of Portland cement. Journal of Materials Science, 10, pp. 1454-1456, 1975.

[5] Ghosh, S.N. and Handoo, S.K., Infrared and Raman spectral studies in cement and concrete (review). Cement and Concrete Research, 10, pp. 771$782,1980$.

[6] Allen, A.J., Thomas, J.J. and Jennings, H.M., Composition and density of nanoscale calcium-silicate-hydrate in cement, Nature Materials, 6, pp. 311316, 2007.

[7] Kantro, D.L., Brunauer, S. and Weise, C.H., The ball mill hydration of tricalcium silicate at room temperature. Journal of Colloid Science, 14, pp. 363-376, 1959.

[8] Ryskin, Y.I., The structure and infrared spectra of acid silicates. Inorganic Materials, 7, pp. 331-344, 1971.

[9] Puertas, F., Goni, S., Hernandez, M.S., Varga, C. and Guerrero, A., Comparative study of accelerated decalcification process among $\mathrm{C} 3 \mathrm{~S}$, grey and white cement pastes. Cement and Concrete Composites, 35, pp. 384391, 2012.

[10] García Lodeiro, I., Macphee, D.E., Palomo, A. and Fernández-Jiménez, A., Effect of alkalis on fresh $\mathrm{C}-\mathrm{S}-\mathrm{H}$ gels. FTIR analysis. Cement and Concrete Research, 39, pp. 147-153, 2009.

[11] García Lodeiro, I., Palomo, A., Fernández-Jiménez, A. and Macphee, D.E., Compatibility studies between N-A-S-H and C-A-S-H gels. Study in the ternary diagram $\mathrm{Na}_{2} \mathrm{O}-\mathrm{CaO}-\mathrm{Al}_{2} \mathrm{O}_{3}-\mathrm{SiO}_{2}-\mathrm{H}_{2} \mathrm{O}$. Cement and Concrete Research, 41, pp. 923-931, 2011.

[12] Bhat, P.A. and Debnath, N.C., Theoretical and experimental study of structures and properties of cement paste: the nanostructural aspects of C-SH. Journal of Physics and Chemistry of Solids, 72, pp. 920-933, 2011.

[13] Ylmén, R., Jäglid, U., Steenari, B-M. and Panas, I., Early hydration and setting of Portland cement monitored by IR, SEM and Vicat techniques. Cement and Concrete Research, 39, pp. 433-439, 2009.

[14] Ylmén, R., Wadsö, L. and Panas, I., Insights into early hydration of Portland limestone cement from infrared spectroscopy and isothermal calorimetry. Cement and Concrete Research, 40, pp. 1541-1546, 2010.

[15] Hughes, T.L., Methven, C.M., Jones, T.G.J., Pelham, S.E., Fletcher, P. and Hall, C., Determining cement composition by Fourier Transform Infrared Spectroscopy. Advanced Cement Based Materials, 2, pp. 91-104, 1995.

[16] Yu, P., Kirkpatrick, R.J., Poe, B., McMillan, P.F. and Cong, X., Structure of calcium silicate hydrate (C-S-H): near, mid and far-infrared spectroscopy. Journal of American Ceramic Society, 82, pp. 742-748, 1999. 
[17] Pajares, I., Martinez-Ramirez, S. and Blanco-Varela, M.T., Evolution of ettringite in presence of carbonate and silicate ions. Cement and Concrete Composites, 25, pp. 861-865, 2003.

[18] Hidalgo Lopez, A., Calvo, J.L.G., Olmo, J.G., Petit, S. and Alonso, MC., Microstructural evolution of calcium aluminate cements hydration with silica fume and fly ash additions by SEM, and mid and near-infrared spectroscopy. Journal of American Ceramic Society, 91, pp. 1258-1265, 2008.

[19] Almeida, E., Balmayore, M. and Santos, T., Some relevant aspects of the use of FT-IR associated techniques in the study of surfaces and coatings, Progress in Organic Coatings, 44, pp. 233-242, 2002.

[20] Chollet, M. and Horgnies, M., Analyses of the surfaces of concrete by Raman and FT-IR spectroscopies: comparative study of hardened samples after demoulding and after organic post-treatment, Surface and Interface Analysis, 43, pp. 714-725, 2011.

[21] Horgnies, M., Willieme, P. and Gabet, O., Influence of the surface properties of concrete on the adhesion of coating: characterization of the interface by peel test and FT-IR spectroscopy, Progress in Organic Coatings, 72, pp. 360-379, 2011. 